\title{
EDUCAÇÃO ALIMENTAR E NUTRICIONAL NO AMBIENTE ESCOLAR: UMA REVISÃO INTEGRATIVA
}

\author{
EDUCACIÓN ALIMENTARIA Y NUTRICIONAL EN EL AMBIENTE ESCOLAR: \\ UNA REVISIÓN INTEGRADORA
}

\author{
FOOD AND NUTRITION EDUCATION IN SCHOOL ENVIRONMENT: AN \\ INTEGRATIVE REVIEW
}

\author{
Aline Tecchio BORSOI ${ }^{1}$ \\ Carla Rosane Paz Arruda TEO ${ }^{2}$ \\ Bruna Roniza MUSSIO ${ }^{3}$
}

RESUMO: A Educação Alimentar e Nutricional é uma estratégia de promoção da saúde e de hábitos alimentares saudáveis. O ambiente escolar surge como um local adequado para desenvolver estas ações. Objetivou-se, através de Revisão Integrativa de Literatura, identificar as características da produção científica sobre a Educação Alimentar e Nutricional no ambiente escolar no período de 2002 a 2013. A amostra desta revisão constituiu-se de 17 artigos. Observou-se que a partir de 2009 tem se dado maior ênfase ao tema. Nove dos estudos selecionados utilizaram metodologias de intervenção, e oito se propuseram a consolidar, na prática de educadores, gestores e donos de cantina escolar, a compreensão sobre Educação Alimentar e Nutricional. As ações realizadas caracterizaram-se como estratégias pouco participativas e críticas, baseadas na transmissão de informações. Conclui-se pela necessidade de abordagens que permitam tratar os problemas alimentares de modo mais amplo na escola, por intermédio de metodologias problematizadoras que superem a mera transmissão de informação.

PALAVRAS-CHAVE: Educação alimentar e nutricional. Saúde escolar. Alimentação escolar. Serviços de saúde escolar.

RESUMEN: La Educación Alimentaria y Nutricional es una estrategia de promoción de la salud y de los hábitos alimentares saludables. El ambiente escolar surge como un lugar adecuado para desarrollar estas acciones. Se objetivó, por medio de la Revisión Integradora de la Literatura, identificar las características de la producción científica sobre la Educación Alimentaria y Nutricional en el ambiente escolar en el periodo de 2002 a 2013. La muestra de esta revisión se constituyó de 17 artículos. Se observó que a partir de 2009 se ha dado más énfasis al tema. Nueve de los estudios seleccionados utilizaron por metodologías de intervención, y ocho se propusieron a consolidar, en la práctica de educadores, gestores y dueños de cantinas escolares, la comprensión sobre

\footnotetext{
${ }^{1}$ Mestre em Ciências da Saúde pela Universidade Comunitária da Região de Chapecó. Nutricionista da Prefeitura Municipal de Cordilheira Alta, SC. Endereço: Avenida Atílio Fontana, 591E, Bairro Efapi, CEP 89990-000, Chapecó, SC, Brasil. E-mail: aline.borsoi@gmail.com

${ }^{2}$ Doutora em Ciência de Alimentos pela Universidade Estadual de Londrina e Docente do Programa de Pós-Graduação em Ciências da Saúde da Universidade Comunitária da Região de Chapecó. Endereço: Avenida Atílio Fontana, 591E, Bairro Efapi, CEP 89990-000, Chapecó, SC, Brasil. E-mail: carlateo@unochapeco.edu.br

${ }^{3}$ Mestre em Educação pela Universidade Federal da Fronteira Sul. Nutricionista da Universidade Federal da Fronteira Sul. Endereço: Avenida Fernando Machado, 108E, Centro, CEP 89802-112, Chapecó, SC, Brasil. E-mail: brunamussio@uffs.edu.br
} 
Educación Alimentaria y Nutricional. Las acciones realizadas se caracterizaron como estrategias poco participativas y críticas basadas en la transmisión de información. Se concluyó por la necesidad de abordajes que permitían tratar los problemas alimentares de modo más amplio en la escuela, por intermedio de metodologías que problematice y superen la simple transmisión de información.

PALABRAS CLAVE: Educación alimentaria y nutricional. Salud escolar. Alimentación escolar. Servicios de salud escolar.

ABSTRACT: The Food and Nutrition Education is a strategy to promote health and healthy eating habits. The school environment rises as a suitable place to develop these actions. Through Integrative Literature Review, we could identify the characteristics of scientific production on the Food and Nutrition Education at school from 2002 to 2013. The sample of this review consisted of 17 articles. It was observed that it has been giving more emphasis to this issue from 2009. Nine of the selected studies opted for intervention methodologies, and eight of them have proposed to consolidate the practice of educators, administrators and school cafeteria owners, the understanding of Food and Nutrition Education. The actions accomplished were characterized as slightly critical and participatory strategies based on the transmission of information. It concludes the need for approaches to treating eating disorders broadly at school, through problem-solving methodologies that go beyond the mere transmission of information.

KEYWORDS: Food and nutrition education. School health. School feeding. School health services.

\section{Introdução}

A Educação Alimentar e Nutricional (EAN) é um campo de ação da Segurança Alimentar e Nutricional (SAN) e da promoção da saúde, e tem sido considerada uma estratégia fundamental para a prevenção e o controle dos problemas alimentares e nutricionais contemporâneos, como as doenças crônicas não transmissíveis e as deficiências nutricionais. A EAN contribui, ainda, para a valorização das diferentes expressões da cultura alimentar, o fortalecimento de hábitos regionais, a redução do desperdício de alimentos e a promoção do consumo sustentável e da alimentação saudável (BRASIL, 2012).

$\mathrm{Na}$ atualidade, tem-se vivenciado um gradativo aumento dos índices de obesidade e outras doenças crônicas não transmissíveis relacionadas ao consumo excessivo e/ou desbalanceado de alimentos pela população, caracterizando um quadro de insegurança alimentar (LEVY et al., 2012). Neste sentido, a EAN aparece como 
estratégia para reverter este quadro, devendo estender-se a todos, desde crianças a idosos, por meio de ações que permeiam a educação formal e informal (BOOG, 2004).

$\mathrm{Na}$ educação formal, o ambiente escolar destaca-se como local adequado e propício para a implementação da EAN, pois é nele que as práticas pedagógicas necessárias para o processo de aprendizagem e melhoria da qualidade de vida ocorrem (BIZZO; LEDER, 2005).

Parafraseando Albuquerque (2012), a escola aparece como local privilegiado para a implementação da EAN, pois possui a função social de formar cidadãos críticos sobre o mundo e as pessoas, conhecedores de diversos assuntos relacionados à vida e à sociedade, dentre eles a alimentação e a nutrição humanas, com a finalidade de construir a cidadania e melhorar a qualidade de vida.

É neste contexto, considerando o papel da escola na direção de viabilizar e qualificar a inserção e a ação do estudante no mundo, tendo como referência a noção de bem comum (GONZÁLEZ; FENSTERSEIFER, 2009), que a escola tem sido um dos espaços mais focados pelas políticas públicas de alimentação e nutrição no Brasil (SANTOS, 2012), conferindo, mais recentemente, especial ênfase ao desenvolvimento de educação alimentar e nutricional neste espaço.

Para abordar a EAN no ambiente escolar, é importante considerar dois profissionais que atuam neste cenário e que possuem influência sobre a alimentação e a nutrição: o nutricionista e o educador, os quais podem oferecer contribuições relevantes. Ademais, é fundamental ampliar as discussões sobre as possibilidades da EAN, seus limites e o modo como é realizada, pois ao mesmo tempo em que ela é apontada como estratégia, sua atuação não está bem definida, resultando em uma grande diversidade de práticas (BRASIL, 2012).

Considerando a relevância da EAN no contexto da escola e a necessidade de ampliar as discussões no âmbito deste tema, incluindo suas práticas, possibilidades e limites, desenvolve-se este trabalho, com o objetivo de identificar as características da produção científica sobre Educação Alimentar e Nutricional no ambiente escolar no período de 2002 a 2013, utilizando-se de uma Revisão Integrativa da Literatura.

Para fins de organização, é oportuno destacar que este trabalho se encontra estruturado em algumas sessões: a metodológica visa a esclarecer os procedimentos por meio dos quais realizou-se a coleta dos dados que baseiam a discussão deste artigo; a seguinte apresenta os resultados desta coleta, discutindo-os sob a ótica de outros autores e estudos; a final busca pontuar as principais conclusões obtidas com a análise realizada. 


\section{Métodos}

Trata-se de um estudo de Revisão Integrativa de Literatura desenvolvido segundo as etapas propostas por Ganong (1987), a saber: elaboração da pergunta de pesquisa; definição dos critérios de inclusão e exclusão dos estudos; seleção dos estudos; inclusão dos estudos selecionados em formato de tabela construída a partir do Microsoft Excel; análise e discussão dos resultados.

A realização do estudo foi norteada pela seguinte questão: Quais as características da produção científica sobre Educação Alimentar e Nutricional no ambiente escolar no período de 2002 a 2013? Para respondê-la, a partir de protocolo de pesquisa elaborado e validado no segundo semestre de 2013, a seguinte estratégia foi utilizada para a busca dos artigos nas bases de dados da Biblioteca Virtual em Saúde (BVS/BIREME), realizada no mês de abril de 2014: "educação alimentar e nutricional" AND ("alimentação escolar" OR "saúde escolar" OR "serviços de saúde escolar").

Para seleção dos artigos foram considerados os seguintes critérios de inclusão: a) período: janeiro de 2002 a dezembro de 2013; b) idioma: português, inglês, espanhol; c) trabalhos publicados apenas no formato de artigos científicos; d) estudos acessíveis on-line em formato completo; e) trabalhos cujo objetivo geral e/ou específicos referiam-se ao objeto deste estudo.

Quanto aos critérios de exclusão, foram considerados os seguintes: a) trabalhos do tipo: revisões bibliográficas não sistematizadas, cartas, resenhas, editoriais; b) publicações do tipo: livros; capítulos de livros; publicações governamentais; boletins informativos; c) trabalhos publicados no formato de teses; dissertações; monografias e trabalhos de conclusão de curso; d) estudos com apenas o resumo disponível on-line; e) estudos cujo objetivo geral e/ou específicos não estavam explicitados ou, quando explícitos, não se referiam ao objeto deste estudo; f) estudos duplicados.

$\mathrm{Na}$ seleção dos artigos, inicialmente foi realizada a busca do quantitativo de trabalhos publicados na BVS, com posterior leitura individual dos títulos e resumos de todos os trabalhos encontrados. Uma vez aplicados os critérios de inclusão e exclusão, foram selecionados e coletados os artigos que compuseram o corpus inicial de análise.

Posteriormente a esta etapa, foi realizada pelas pesquisadoras a revisão dos estudos pré-selecionados, por meio de leitura flutuante, que ocorreu de modo independente. Os trabalhos excluídos por todas as pesquisadoras foram retirados do 
corpus de análise; aqueles que não foram excluídos por unanimidade passaram por nova análise, realizada em conjunto pelas pesquisadoras, para definição de consenso. Por fim, os artigos incluídos na Revisão Integrativa de Literatura alimentaram uma matriz elaborada para organização e análise dos dados.

Com a leitura em profundidade dos artigos na íntegra, observaram-se as características da Educação Alimentar e Nutricional no ambiente escolar, construindo-se uma síntese descritiva dos achados, a qual é apresentada na próxima sessão.

\section{Resultados e discussão}

Segundo os procedimentos metodológicos referidos, foram inicialmente localizadas 78 publicações. Contudo, da aplicação dos critérios de inclusão e exclusão adotados, 23 foram selecionados para compor o corpus inicial de análise, sendo que os outros 55 trabalhos não faziam parte do período estipulado ou não estavam disponíveis em texto completo on-line ou não correspondiam ao formato de artigo científico, motivos pelos quais foram excluídos. Após realizar a análise criteriosa dos 23 artigos, seis deles foram excluídos por não se referirem ao objeto deste estudo. Assim, chegouse ao total de 17 artigos, os quais são apresentados no Quadro 1, segundo a ordem cronológica de publicação.

Quadro 1 - Estudos sobre EAN no ambiente escolar no período de 2002 a 2013, segundo o periódico, autores, ano e país de publicação.

\begin{tabular}{|c|c|c|c|c|}
\hline $\mathrm{E}^{\mathrm{a}}$ & Título & Revista & Autores, Ano & País \\
\hline 1 & $\begin{array}{l}\text { Conhecimentos, atitudes e práticas de } \\
\text { professores de ciclo básico, expostos e } \\
\text { não expostos a curso de Educação } \\
\text { Nutricional }\end{array}$ & Revista Nutrição & $\begin{array}{ll}\text { DAVANÇO; } & \text { TADDEI; } \\
\text { GAGLIANONE, } 2004 & \end{array}$ & Brasil \\
\hline 2 & $\begin{array}{l}\text { A escola promovendo hábitos } \\
\text { alimentares saudáveis: uma proposta } \\
\text { metodológica de capacitação para } \\
\text { educadores e donos de cantina escolar }\end{array}$ & $\begin{array}{l}\text { Cadernos de Saúde } \\
\text { Pública }\end{array}$ & SCHMITZ et al., 2008 & Brasil \\
\hline 3 & $\begin{array}{l}\text { Avaliação de um programa para } \\
\text { promoção de hábitos alimentares } \\
\text { saudáveis em escolares de } \\
\text { Florianópolis, Santa Catarina, Brasil }\end{array}$ & $\begin{array}{l}\text { Revista Brasileira de } \\
\text { Saúde Materno Infantil }\end{array}$ & $\begin{array}{l}\text { GABRIEL; } \\
\text { VASCONCELOS, } 2008\end{array}$ & Brasil \\
\hline 4 & $\begin{array}{l}\text { Construção de metodologia de } \\
\text { capacitação em alimentação e nutrição } \\
\text { para educadores }\end{array}$ & Revista de Nutrição & BERNARDON et al., 2009 & Brasil \\
\hline 5 & $\begin{array}{l}\text { Educação nutricional em escolas de } \\
\text { ensino fundamental do município de } \\
\text { Guarulhos-SP }\end{array}$ & O mundo da Saúde & $\begin{array}{l}\text { IULIANO; } \quad \text { MANCUSO; } \\
\text { GAMBARDELLA, } 2009\end{array}$ & Brasil \\
\hline 6 & Intervenções nutricionais em escolares & $\begin{array}{l}\text { Revista Brasileira em } \\
\text { Promoção da Saúde }\end{array}$ & ANZOLIN et al., 2010 & Brasil \\
\hline
\end{tabular}


Promoção da alimentação saudável para escolares: aprendizados e percepções de um grupo operativo

8 A educação nutricional nas séries iniciais de escolas públicas estaduais de dois municípios do oeste de Santa Catarina

9 Avaliação de programa de prevenção de obesidade em adolescentes de escolas públicas

10 Utilidad de los programas de educación nutricional para prevenir la obesidad infantil através de un estudio piloto en Soria

11 Avaliação antropométrica e por bioimpedância de um programa de educação nutricional para escolares na faixa etária de 7-14 anos durante o período de 10 meses

12 Un juego de cartas durante los recreos escolares mejora los hábitos alimentarios en adolescentes

13 Efeito de ações educativas no consumo de alimentos no ambiente escolar

14 Alimentação na escola e autonomia desafios e possibilidades.

15 A experiência da Oficina Permanente de Educação Alimentar e em Saúde (OPEAS): formação de profissionais para a promoção da alimentação saudável nas escolas.

16 Redução do uso de açúcar em escolas públicas: ensaio randomizado por conglomerados.

17 Formação de coordenadores pedagógicos em alimentação escolar: um relato de experiência.

\begin{tabular}{|c|c|c|c|}
\hline Nutrire & & BOTELHO et al., 2010 & Brasil \\
\hline Nutrire & & $\begin{array}{l}\text { PICCOLI; JOHANN; CORRÊA, } \\
2010\end{array}$ & Brasil \\
\hline $\begin{array}{l}\text { Revista } \\
\text { Pública }\end{array}$ & de Saúde & VARGAS et al., 2011. & Brasil \\
\hline Nutrición & Hospitalaria & GALLARDO-PÉREZ et al., 2011 & Espanha \\
\hline $\begin{array}{l}\text { Journal } \\
\text { Growth } \\
\text { Developm }\end{array}$ & $\begin{array}{l}\text { of Human } \\
\text { and } \\
\text { ent }\end{array}$ & FEFERBAUM et al., 2012 & Brasil \\
\hline Nutrición & Hospitalaria & $\begin{array}{l}\text { PÉREZ- LÓPEZ; DELGADO- } \\
\text { FERNÁNDEZ, } 2012\end{array}$ & Espanha \\
\hline Nutrire & & PRADO et al., 2012 & Brasil \\
\hline $\begin{array}{l}\text { Ciência } \\
\text { Coletiva }\end{array}$ & e Saúde & BARBOSA et al., 2013 & Brasil \\
\hline $\begin{array}{l}\text { Ciência } \\
\text { Coletiva }\end{array}$ & Saúde & $\begin{array}{l}\text { JUZWIAK; CASTRO; BATISTA, } \\
2013\end{array}$ & Brasil \\
\hline $\begin{array}{l}\text { Revista } \\
\text { Pública }\end{array}$ & Saúde & SOUZA et al., 2013 & Brasil \\
\hline $\begin{array}{l}\text { Ciência } \\
\text { Coletiva }\end{array}$ & e Saúde & SANTOS et al., 2013 & Brasil \\
\hline
\end{tabular}

${ }^{a}$ E: estudo

Reforçando a importância crescente dada à EAN atualmente, observa-se (Quadro 1) que 14 dos 17 estudos foram publicados a partir do ano de 2009, o que resulta da maior ênfase dada ao tema nos últimos anos, contribuindo para o aumento progressivo do interesse sobre a temática.

Santos (2012) destaca que, a partir de 2006, a EAN vem sendo alvo de reflexão e debate. Isso pode ser atribuído à publicação da Portaria Interministerial $\mathrm{n}^{\mathrm{o}} 1010 \mathrm{em}$ 2006 (BRASIL, 2006), cujo objetivo foi o de instituir diretrizes para a promoção da alimentação saudável nas escolas. Para este fim, foi indicada a necessidade de incorporação do tema 'alimentação saudável' no projeto pedagógico da escola. Além disso, a alimentação escolar, referindo-se a toda alimentação que os sujeitos acessam na escola, também tem tido visibilidade neste período por conta do estabelecimento de leis 
e normas que englobam a importância de práticas alimentares saudáveis neste espaço, a exemplo da Lei no 11.947/2009 (BRASIL, 2009a), da Resolução FNDE nº 38/2009 (BRASIL, 2009b) e da Resolução FNDE nº 26/2013 (BRASIL, 2013).

Verificou-se que nove dos estudos selecionados assumiram como referência metodológica os processos de intervenção, oito com escolares (E3, E6, E7, E9, E10, E11, E12, E13) e um com merendeiras (E16), estando seus objetivos predominantemente situados no âmbito de avaliar os resultados de uma determinada intervenção no ambiente escolar. Estes estudos apresentam uma prática de EAN fundamentada na relação entre alimentos e sua composição nutricional, por meio de metodologias tecnicistas centradas em um único protagonista detentor do conhecimento, o nutricionista.

Diez-Garcia (2011) sinaliza que a EAN é um tema interdisciplinar que abrange redes conceituais provindas de diversos campos do saber relacionados à alimentação, como a do direito humano, a biológica, a psicossocial, a cultural, a ambiental e a econômica, as quais devem ser integradas para que se supere uma visão estritamente tecnicista, focada apenas no aspecto nutricional da alimentação.

Têm sido fomentadas discussões sobre o importante papel da EAN a fim de amenizar e controlar o atual quadro de má nutrição e excesso de peso, bem como de promover alimentação e nutrição adequada com especial atenção à criança em idade escolar.

Em contrapartida aos estudos de intervenção, surgiram oito estudos na direção de consolidar, na prática de gestores, educadores, coordenadores e donos de cantina escolar a compreensão do papel do alimento e da EAN no ambiente escolar (E1, E2, E4, E5, E8, E14, E15, E17). É a partir destas duas categorias que os estudos serão apresentados e discutidos a seguir.

\section{Estudos de intervenção}

Analisando a categoria dos estudos de intervenção, verifica-se que oito deles foram realizados com escolares, na faixa dos seis aos 17 anos de idade, o que provavelmente decorre do consenso de que os programas de EAN sejam aplicados e iniciados desde a infância, no sentido de contribuir para a formação de hábitos alimentares saudáveis duradouros (BIZZO; LEDER, 2005). Além disso, pode-se inferir 
que a faixa etária abordada nestes estudos seja alvo de especial atenção por corresponder aos anos de obrigatoriedade da educação básica, os quais, a partir da Emenda $\mathrm{n}^{\circ} 59$ de 2009 (BRASIL, 2009c), passaram a abranger até os 17 anos de idade, tornando a alimentação escolar um direito deste público também.

Encontrou-se apenas um estudo (E16) em que o foco das ações de EAN esteve colocado nas merendeiras, com o objetivo de analisar a eficácia de ações de EAN desenvolvidas com estas profissionais na redução da adição de açúcar na alimentação escolar e no autoconsumo (SOUZA et al., 2013). Acredita-se que este tipo de estudo pode exercer um papel estruturador na medida em que avalia o potencial de compreensão e mudança de hábito de uma figura fundamental para a alimentação escolar que é a merendeira. Se avaliarmos que a melhoria dos hábitos alimentares depende tanto de conhecimentos em relação aos alimentos quanto da possibilidade de acesso a eles, perceberemos a EAN desenvolvida com estas profissionais como essencial para a garantia da oferta de refeições mais saudáveis na escola.

Um estudo (E7) se destacou dos demais, pois, além de avaliar o efeito de ações de EAN, evidenciou a preocupação com um processo que proporcionasse a participação dos alunos. Neste estudo, objetivou-se também avaliar a percepção dos escolares, utilizando como referência as técnicas de grupo operativo. As discussões no grupo eram voltadas à promoção da alimentação saudável com vistas à construção do conhecimento e foram conduzidas por acadêmicas de nutrição (BOTELHO et al., 2010).

A presença das acadêmicas de nutrição nos grupos operativos conduz à reflexão sobre a disciplina de Educação Nutricional nos currículos dos cursos de graduação em nutrição, a qual apresenta certa fragilidade, de acordo com Ferreira e Magalhaes (2007), que constataram a predominância de um modelo tradicional de educação nutricional, concentrada no saber técnico específico do campo da nutrição, não utilizando técnicas e métodos problematizadores e construtivistas, que poderiam contribuir para a formação de indivíduos críticos e conscientes de suas responsabilidades como cidadãos.

Para embasar a EAN na escola, é importante atentar para o tema que a enuncia: a educação. A educação compreende um meio responsável pela construção de conhecimentos capazes de potencializar práticas sociais (SAVIANI, 2009). Assim, o educador em EAN, seja ele o professor ou o nutricionista, deve ser um mediador, que primeiramente precisa compreender a alimentação enquanto estratégia pedagógica na escola, para então promover a construção destes conhecimentos junto aos educandos. Romper os limites entre os conhecimentos sobre educação dos educadores e os de 
nutrição dos nutricionistas pode ser um dos caminhos para a superação dos limites da EAN, tanto no âmbito da escola quanto no da formação destes profissionais (BARBOSA et al., 2013).

Analisando as metodologias dos estudos de intervenção para o desenvolvimento das atividades de EAN, um estudo (E9) diferenciou-se por utilizar o grupo focal com escolares, antecedendo o planejamento das atividades, com o objetivo de identificar as temáticas de interesse sobre saúde e alimentação. Os docentes também participaram, apresentando opiniões e sugestões sobre as atividades propostas, com o intuito de adequá-las à realidade e ao cotidiano da escola (VARGAS et al., 2011). Por conseguinte, estimulou-se a comunidade escolar a pensar coletivamente sobre o cotidiano e sobre a cultura que se institui na escola.

A metodologia utilizada no estudo supracitado ganha relevância na medida em que para estimular a mudança de comportamentos é necessário, primeiramente, que se entenda o contexto no qual são construídos os significados e a importância a eles atribuída pelos seus agentes. Enquanto pequena parcela do significado do contexto comportamental é de cunho pessoal e particular, grande parte é culturalmente condicionada e socialmente construída. Esta metodologia - do grupo focal - permite a aproximação da população e a compreensão dos símbolos e dos significados por ela utilizados na apreensão da realidade (IERVOLINO; PELICIONI, 2001).

Neste sentido, "a EAN deve ampliar sua abordagem para além da transmissão de conhecimento e gerar situações de reflexão sobre as situações cotidianas, busca de soluções e práticas de alternativas" (BRASIL, 2012, p. 28). Barbosa et al. (2013) propõem que é necessário estranhar que uma prática como a alimentação na escola passe despercebida, e estranhar, neste caso, significa trazer o tema alimentação na escola para a mesa de debate.

Cabe salientar que um estudo de intervenção (E12), realizado na Espanha, utilizou o período do intervalo para desenvolver uma atividade educativa utilizando a metodologia do jogo de cartas (PÉREZ-LÓPEZ; DELGADO-FERNÁNDEZ, 2012), o que reforça a ideia de que o horário de distribuição da alimentação escolar pode representar uma oportunidade para as atividades de EAN (IULIANO; CERVATOMANCUSO; GAMBARDELLA, 2009). De acordo com a Resolução FNDE nº 26/2013 (BRASIL, 2013), o alimento deve ser utilizado como ferramenta pedagógica para a EAN, o que foi pouco observado nos estudos selecionados para esta pesquisa. De acordo com Teo e Monteiro (2012), é preciso pensar em ações de EAN em que o ponto 
articulador seja a alimentação concreta distribuída na escola. De modo objetivo, sinaliza-se que a comum prática de comer deve se dar ao mesmo tempo em que a prática de educar para e pelo ato de comer (BARBOSA et al., 2013).

Os demais estudos de intervenção (E3, E6, E11, E13) utilizaram metodologias como aulas expositivas, palestras, oficinas, teatros, oficinas culinárias, atividades lúdicas, vídeos, cartazes e jogos de conhecimento. Os temas mais abordados foram pirâmide alimentar, valor nutritivo dos alimentos, alimentação saudável e fontes alimentares, que foram trabalhados de forma isolada. Observa-se, nestes estudos, uma ênfase maior na informação com enfoque predominantemente biológico, a partir do qual são tratadas as práticas alimentares.

De acordo com o Marco de Referência da Educação Alimentar e Nutricional (BRASIL, 2012), a EAN terá melhores resultados se articular temas de caráter estrutural que abranjam aspectos desde a produção até o consumo dos alimentos, pois sua capacidade de gerar impacto depende das ações articuladas entre as dimensões do que o indivíduo pode definir e alterar com aquelas que o ambiente condiciona e possibilita. Ademais, é essencial assumir a cultura alimentar como aspecto de relevância.

Em relação à articulação de temas, constatou-se que um dos estudos de intervenção (E3) abordou, como parte das atividades de EAN, a separação e reciclagem do lixo, utilizando embalagens de alimentos descartadas pelos escolares (GABRIEL; SANTOS; VASCONCELOS, 2008), o que indica a preocupação em abranger as várias dimensões da EAN, incluindo desde as práticas alimentares até a geração e destinação do lixo.

Quanto aos principais métodos empregados para a avaliação das intervenções realizadas, observou-se a predominância de indicadores antropométricos e de consumo alimentar (E3, E6, E9, E10, E11, E13). Tal perspectiva se baseia na hipótese de que a apreensão de saber instituído leva à aquisição de novos comportamentos alimentares (GAZINELLI; GAZINELLI; REIS; PENNA, 2005), com consequente impacto benéfico no estado nutricional, em uma relação linear de causalidade.

O tempo de duração das ações de EAN nos estudos avaliados variou de três a 10 meses. Os resultados do estudo de Prado et al. (2012) reforçam que a eficácia de intervenções nutricionais não depende somente do tempo de intervenção e sim de outros fatores, chamados de fatores facilitadores, além de aspectos ligados ao próprio indivíduo. Um dos fatores facilitadores é a sensibilização de toda comunidade escolar, envolvendo pais, estudantes e educadores. Além disso, as abordagens educativas e 
pedagógicas apoiadas em EAN devem auxiliar processos ativos que possibilitem a integração permanente entre a teoria e a prática. O caráter permanente aponta que a EAN é prática que precisa perpassar o curso da vida, atendendo às demandas específicas que o indivíduo apresente nas diferentes etapas do processo de viver (BRASIL, 2012).

Há necessidade de o nutricionista romper o modelo tecnicista tradicional para estabelecer uma relação de diálogo entre o saber popular e o técnico, estendendo atividades educativas para a promoção da saúde e da alimentação saudável do ambiente escolar para as famílias e comunidades, além da ênfase à sensibilização e ao envolvimento de toda comunidade escolar, principalmente no que se refere à atuação do professor (COSTA; RIBEIRO; RIBEIRO, 2001).

É fundamental, no âmbito da EAN no ambiente escolar, associar ações que envolvam os professores diretamente vinculados ao escolar, assim como é premente que seja superado o ainda tão presente olhar biológico sobre a alimentação. É nesta direção que se apresenta a próxima categoria de estudos, que convergem em termos do público com que foram desenvolvidos, incluindo educadores, diretores e coordenadores pedagógicos e os donos de cantina, no sentido de ampliar as discussões e qualificar a prática de EAN no ambiente escolar.

\section{Estudos com educadores, gestores e donos de cantina escolar}

O primeiro estudo desta categoria surge em 2004 (E1) e aponta o professor como 'membro da saúde escolar'. Para os autores, é importante que professores aprendam conceitos corretos sobre nutrição, pois estes atores são a base para o desenvolvimento de ações educativas na escola. $\mathrm{O}$ estudo desenvolve um programa de formação para os educadores sobre nutrição, atividade física e saúde. Em sua metodologia descreve que “os conteúdos relacionados à área da nutrição visaram transmitir conhecimentos que gerassem atitudes e práticas relacionadas a hábitos alimentares adequados, enfocando regras gerais para uma dieta balanceada" (DAVANÇO; TADDEI; GAGLIANONE, 2004, p.180). Constata-se que a preocupação, nesta ocasião, parecia estar centrada na transmissão de informações aos educadores para que estes desenvolvessem atividades de EAN em sala de aula, retransmitindo-as aos escolares.

Em 2008 surge um estudo (E2) com outra proposta de capacitação com educadores, em que se adotou uma abordagem sócio-construtivista e em conformidade 
com os Parâmetros Curriculares Nacionais (BRASIL, 1997). O objetivo da metodologia aplicada na capacitação foi a construção do conhecimento, apresentando um modelo problematizador de EAN, distanciando-se dos modelos tradicionais que assumiam uma lógica mais próxima do 'adestramento' (SCHMITZ, 2008). Desta forma, marca-se um discurso em torno da EAN transformadora, assumindo uma perspectiva problematizadora e crítica com vistas a ultrapassar uma visão puramente instrumental.

Neste estudo (E2), os autores propuseram também a capacitação dos donos de cantinas escolares, público raramente abordado na literatura científica sobre EAN. Ressalta-se que este fato pode estar relacionado com a diminuição do número de cantinas escolares, em virtude da restrição da venda de determinados alimentos considerados não saudáveis, conforme legislação específica de nível estadual e/ou municipal (BRASIL, 2007).

O debate em torno da regulamentação ou da adoção de medidas que possam transformar as cantinas e os serviços de alimentação escolar em locais que garantam o fornecimento de alimentos e refeições saudáveis, com o aumento da oferta de frutas, legumes e verduras e a restrição de alimentos e bebidas com alto teor de gordura, açúcar e sódio, vem assumindo dimensão internacional. Inúmeros países estão construindo alternativas para o ambiente escolar, procurando intervir nos elevados índices de sobrepeso e obesidade infantil (BRASIL, 2007).

A partir de 2009 têm-se dois estudos (E5, E8) que retomam o modelo da EAN tradicional com foco nos educadores, gestores e coordenadores pedagógicos. Um deles (E8) teve por objetivo verificar como os educadores buscam informações sobre alimentação saudável e analisar a presença dos temas transversais dos Parâmetros Curriculares Nacionais nos Projetos Político-Pedagógicos das escolas. Este estudo evidenciou que os educadores utilizam como principal fonte de informação sobre o tema 'alimentação saudável' o livro didático e a internet (PICCOLI; JOHANN; CORRÊA, 2010). Além disso, foi evidenciado que os professores relacionam este tema somente com a disciplina de Ciências, demonstrando o desconhecimento de que, a partir de 2006, o PNAE passou a incluir em suas diretrizes a EAN no processo de ensinoaprendizagem (BRASIL, 2006).

Nota-se, no outro estudo mencionado (E5), que as atividades de EAN desenvolvidas na escola se limitam a aulas tradicionais e que a alimentação escolar é pouco reconhecida como atividade pedagógica pelos gestores (IULIANO, MANCUSO, GAMBARDELLA, 2009). Diante disso, parece interessante pensar que a EAN nas 
escolas demanda um aporte conceitual e técnico dos vários atores sociais envolvidos, mobilizando diferentes campos do saber. É necessária uma compreensão ampliada sobre a EAN que permita percebê-la para além das atividades ligadas à alimentação e nutrição. A EAN requer uma abordagem integrada que articule as práticas alimentares a questões relativas à disponibilidade e ao acesso aos alimentos, incluindo os condicionantes dos comportamentos envolvidos nas escolhas alimentares, as formas de produção, preparo e consumo destes alimentos, permeadas por aspectos ambientais, sociais, culturais e históricos. Ou seja, a EAN precisa ser discutida enquanto estratégia que compreende a alimentação em seu contexto social, biológico, cultural, político e econômico (BRASIL, 2012), historicamente datado, e que deve ser abordada de forma articulada para construir conhecimento e práticas que levem a escolhas alimentares mais adequadas e autônomas.

Os dois estudos supracitados (E5, E8) demonstram a pertinência de que sejam desenvolvidas continuamente capacitações sobre EAN com este público, utilizando estratégias que busquem a problematização do papel do educador como promotor da saúde no ambiente escolar, contribuindo para a construção de recursos que os permitam enfrentar questões relacionadas à alimentação e nutrição no espaço da escola.

Os educadores conhecem e convivem diariamente com os estudantes em uma relação simultânea de construção de conhecimento e de troca, motivo pelo qual se propõe que eles tenham um papel importante na configuração e no estabelecimento da EAN. Para tanto, reforça-se que o conhecimento e a reflexão do educador no âmbito desta temática são essenciais (DOMENE, 2008).

O estudo de Bernardon et al. (2009) verificou que é necessário melhorar o conhecimento sobre alimentação e nutrição dos educadores, como um primeiro passo para a promoção da saúde no ambiente escolar. Contudo, segundo este estudo (E4), para que o educador se transforme em agente promotor de hábitos alimentares saudáveis, é essencial que desenvolva, além dos conhecimentos teóricos de alimentação e nutrição, consciência da importância da sua atuação na formação dos hábitos alimentares do escolar. Desta forma, o estudo vai em direção à construção de uma capacitação em educação nutricional para educadores inserida na concepção de educação permanente a partir dos sujeitos psicossociais vinculados ao seu contexto cotidiano, sendo desenvolvida de acordo com as condições socioeconômicas da comunidade, contemplando os conceitos de diálogo, participação, conscientização e ação. 
Em 2013, duas publicações (E15, E17) adotam esta perspectiva. Uma delas (E17) com o objetivo de relatar a experiência de formação de coordenadores pedagógicos em alimentação escolar, em que se priorizou o uso de abordagens metodológicas problematizadoras, estimulando a reflexão desses profissionais sobre suas realidades (SANTOS et al., 2013). O objetivo delineado para a formação foi o de sensibilizar e orientar os coordenadores pedagógicos a construir, junto com a comunidade escolar, práticas educativas voltadas para a transversalização do tema alimentação e nutrição enquanto projeto pedagógico. $\mathrm{O}$ estudo destaca que, muito embora os coordenadores pedagógicos não necessariamente trabalhassem diretamente com os estudantes, visou estimular a sensibilidade desses atores para com o professor, na sua efetiva prática docente, o que poderia concretizar o tratamento transversal e transdisciplinar dos temas relativos à alimentação e nutrição.

A outra publicação (E15), de Juzwiak, Castro e Batista (2013), desenvolvida com educadores, diretores, assistentes de direção, coordenadores pedagógicos e graduandos de nutrição, objetivou apresentar a experiência da Oficina Permanente de Educação Alimentar e Nutricional e em Saúde, em um espaço de articulação dos profissionais envolvidos na promoção da alimentação saudável na escola. Os autores apontam que a relação entre educadores e nutricionistas se apresenta distante, o que dificulta a realização de atividades interprofissionais/interdisciplinares no ambiente escolar.

Atenta-se que com o avançar dos estudos há uma articulação e aproximação entre os diversos atores da escola. Barbosa et al. (2013) sugerem algumas reflexões para que o processo de EAN seja efetivo e alcance os resultados almejados, e uma delas é que não é só o estudante que precisa ser educado do ponto de vista da alimentação, mas gestores, professores, merendeiras, agricultores familiares, nutricionistas, coordenadores pedagógicos e também os pais. Neste sentido, destaca-se que nenhum dos estudos selecionados nesta pesquisa estendeu a EAN até os pais ou outros familiares e cuidadores do escolar. É necessário, reforça-se, pensar em ações que envolvam estes outros agentes sociais como importante força de mudança de comportamento dos estudantes (SANTOS, 2005). Registra-se, ainda, outra omissão relevante em termos dos agentes que poderiam ser incorporados no âmbito da EAN: os agricultores familiares, na condição de fornecedores de gêneros para a alimentação escolar, também não foram abordados nos estudos avaliados. 
Diante dos estudos selecionados e da diversidade de abordagens metodológicas relatadas, pondera-se que é necessário avançar nas discussões sobre a EAN e sobre a forma como é planejada e desenvolvida no universo escolar. Além disso, argumenta-se que os diversos atores da comunidade escolar devam ser contemplados, no intuito de que sejam identificados e superados os limites e desafios da EAN.

\section{Conclusão}

A realização desta pesquisa possibilitou a análise das características da EAN no ambiente escolar. A revisão da literatura não deixa dúvidas sobre a importância da EAN na escola e sobre a pertinência de que seja desencadeado um processo de reflexão sobre suas possibilidades e limites, como forma de contribuir para avanços neste campo.

Os estudos apontam que a EAN no ambiente escolar é desenvolvida com diferentes atores sociais, incluindo estudantes, educadores, gestores escolares e comerciantes de alimentos. Contudo, entre estas categorias, observou-se um predomínio, no período avaliado, de estudos de intervenção com foco nos escolares, os quais se caracterizaram pela adoção de estratégias pouco participativas e críticas baseadas principalmente na transmissão de informações.

Esse modelo de ensino-aprendizagem tradicional em relação à promoção da alimentação saudável diminui nos estudos conforme se estabelecem parcerias e se desenvolvem atividades práticas, incorporando ações e temáticas multidisciplinares. Constatou-se que a alimentação escolar, apesar de representar a mais antiga política pública brasileira na área da alimentação e da nutrição, vigente ininterruptamente há mais de 60 anos, é pouco concebida e, portanto, pouco utilizada como estratégia de EAN. Esta observação reforça a necessidade de fortalecer, neste ambiente, uma nova compreensão de alimentação escolar, que vai além da refeição fornecida.

A maioria dos artigos avaliados foi de intervenção, porém, por se tratarem de estudos no campo da educação, tal metodologia apresentou limitações para a EAN, tais como o curto tempo entre a intervenção e a avaliação.

Destaca-se ainda que há um hiato de três anos no período considerado neste trabalho, não tendo sido localizados estudos sobre EAN entre 2005 e 2007. Porém, a partir de 2009 observa-se um aumento nos estudos sobre a temática, reforçando a relevância crescente do tema nos últimos anos. Principalmente os estudos mais recentes 
desenvolvidos com educadores propuseram a construção da EAN com diálogo, participação, conscientização e transformação, com uma proposta de aproximação entre nutricionistas e educadores, podendo ser uma forma de superação dos limites da EAN no ambiente escolar.

Portanto, sugere-se que um dos grandes desafios da EAN pode ser o desenvolvimento de abordagens que permitam abarcar as questões alimentares em uma perspectiva ampliada, por meio de estratégias problematizadoras que superem a lógica reducionista da transmissão de informação. Outras possibilidades existem e devem ser estimuladas para que se possa desenvolver mecanismos inovadores de promoção de hábitos alimentares saudáveis transversais, contextualizados e mais bem-sucedidos no ambiente escolar e a partir dele.

AGRADECIMENTOS: À Dra. Maria Elisabeth Kleba da Silva, pela validação do protocolo de pesquisa.

\section{REFERÊNCIAS}

ALBUQUERQUE, A.G. Conhecimentos e práticas de educadores e nutricionistas sobre a educação alimentar e nutricional no ambiente escolar. 2012, 102p.

Dissertação (Mestrado em Nutrição) - Universidade Federal de Pernambuco, Recife.

ANZOLIN, C. et al. Intervenções nutricionais em escolares. Revista Brasileira em Promoção da Saúde, v. 23, n. 4, p. 297-306, 2010.

BARBOSA, N.V.S. et al. Alimentação na escola e autonomia - desafios e possibilidades. Ciência \& Saúde Coletiva, v.18, n.4, pp. 937-945, 2010.

BERNARDON, R. et al. Construção de metodologia de capacitação em alimentação e nutrição para educadores. Revista de Nutrição, v. 22, n. 3, p. 389-398, 2009.

BIZZO, M.L.G.; LEDER, L. Educação nutricional nos parâmetros curriculares nacionais para o ensino fundamental. Revista de Nutrição, v.18, n.5, pp. 661-667, 2005.

BOOG, M.C.F. Contribuições da Educação nutricional à Construção da Segurança Alimentar. Saúde em Revista, v.13, n.6, p. 17-23, 2004.

BOTELHO, L.P. et al. Promoção da alimentação saudável para escolares: aprendizados e percepções de um grupo operativo. Nutrire: Revista da Sociedade Brasileira de Alimentação e Nutrição, v. 35, n. 2, p. 103-116, 2010. 
BRASIL. Secretaria de Educação Fundamental. Parâmetros curriculares nacionais: introdução aos parâmetros curriculares nacionais. Brasília: MEC/SEF, 1997.

1.010 .

Ministério da Saúde. Ministério da Educação. Portaria Interministerial no

08 de maio de 2006. Institui as diretrizes para a Promoção da Alimentação Saudável nas Escolas de educação básica das redes públicas e privadas, em âmbito nacional. Diário Oficial da União, 09 mai. 2006.

Ministério da Saúde. Secretaria de Atenção à Saúde. Departamento de Atenção Básica. Experiências estaduais e municipais de regulamentação da comercialização de alimentos em escolas no Brasil: identificação e sistematização do processo de construção e dispositivos legais adotados / Ministério da Saúde, Secretaria de Atenção à Saúde, Departamento de Atenção Básica, 2007.

a. Lei $\mathrm{n}^{\circ} 11947$ de 16 de junho de 2009. Dispõe sobre o atendimento da alimentação escolar e do Programa Dinheiro Direto na Escola aos alunos da educação básica; altera as Leis nos 10.880, de 9 de junho de 2004, 11.273, de 6 de fevereiro de 2006, 11.507, de 20 de julho de 2007; revoga dispositivos da Medida Provisória no 2.178-36, de 24 de agosto de 2001, e a Lei no 8.913, de 12 de julho de 1994; e dá outras providências. Diário Oficial da União, Brasília, DF, 17 de junho de 2009. Seção 1, p.2.

b. Resolução/CD/FNDE no 38, de 16 de julho de 2009. Dispõe sobre o atendimento da alimentação escolar aos alunos da educação básica no Programa Nacional de Alimentação Escolar - PNAE. Diário Oficial da União, 16 jun. 2009.

c. Casa Civil. Subchefia para Assuntos Jurídicos. Emenda Constitucional $\mathbf{n}^{\mathbf{0}}$ 59, de 11 de novembro de 2009. Acrescenta $\S 3^{\circ}$ ao art. 76 do Ato das Disposições Constitucionais Transitórias para reduzir, anualmente, a partir do exercício de 2009, o percentual da Desvinculação das Receitas da União incidente sobre os recursos destinados à manutenção e desenvolvimento do ensino de que trata o art. 212 da Constituição Federal, dá nova redação aos incisos I e VII do art. 208, de forma a prever a obrigatoriedade do ensino de quatro a dezessete anos e ampliar a abrangência dos programas suplementares para todas as etapas da educação básica, e dá nova redação ao $\S 4^{\circ}$ do art. 211 e ao $\S 3^{\circ}$ do art. 212 e ao caput do art. 214 , com a inserção neste dispositivo de inciso VI.

Ministério do Desenvolvimento Social e Combate à Fome. Marco de referência de educação alimentar e nutricional para as políticas públicas. Brasília, DF: MDS; Secretaria Nacional de Segurança Alimentar e Nutricional; 2012.

Resolução/CD/FNDE n 26, de 17 de junho de 2013 Dispõe sobre o atendimento da alimentação escolar aos alunos da educação básica no âmbito do Programa Nacional de Alimentação Escolar - PNAE. Diário Oficial da União 2013, 17 jun. 2013.

COSTA, E.Q.; RIBEIRO, V.M.B; RIBEIRO, E.C.O. Programa de alimentação escolar: espaço de aprendizagem e produção de conhecimento. Revista de Nutrição, v.14, n.3, p. 225-229, 2001. 
DAVANCO, G.M; TADDEI, J.A.A. C.; GAGLIANONE, C.P. Conhecimentos, atitudes e práticas de professores de ciclo básico, expostos e não expostos a Curso de Educação Nutricional. Revista de Nutrição, v.17, n.2, p. 177-184, 2004.

DIEZ-GARCIA, R.W. Mudanças alimentares; implicações práticas, teóricas, metodológicas. In DIEZ-GARCIA, R.W.; CERVATO-MANCUSO, A.M. Mudanças alimentares e Educação Alimentar e Nutricional. 1ed. Rio de Janeiro: Ed. Guanabara Koogan, 2011, 3p.

DOMENE, S.M.A. A escola como ambiente de promoção da saúde e educação nutricional. Psicologia USP, v.19, n.4, p. 505-517, 2008.

FEFERBAUM, R. et al. Avaliação antropométrica e por bioimpedância de um programa de educação nutricional para escolares na faixa etária de 7 a 14 anos durante o período de 10 meses. Journal of Human Growth and Development, v. 22, n.3, p. 283-290, 2012.

FERREIRA, V.A.; MAGALHAES, R. Nutrição e promoção da saúde: perspectivas atuais. Cadernos de Saúde Pública, v.23, n.7, p. 1674-168, 2007.

GABRIEL, C.G.; SANTOS, M.V.; VASCONCELOS, F.A.G. Avaliação de um programa para promoção de hábitos alimentares saudáveis em escolares de Florianópolis, Santa Catarina, Brasil. Revista Brasileira de Saúde Materno Infantil, v.8, n.3, p. 299-308, 2008.

GANONG, L.H. Integrative reviews of nursing. Nursing and Health, v.10, n. 1, p. 1$11,1987$.

GAZZINELLI, M.F. et al. Educação em saúde: conhecimentos, representações sociais e experiências da doença. Cadernos de Saúde Pública, v.21, n.1, p. 200-206, 2005.

GONZÁLEZ, F.J.; FENSTERSEIFER, P.E. Entre o "não mais" e o "ainda não": pensando saídas do não-lugar da EF escolar I. Cadernos de Formação RBCE, v. 1, p. 9-24, 2009.

IERVOLINO, S.A.; PELICIONI, Maria, C.F. A utilização do grupo focal como metodologia qualitativa na promoção da saúde. Revista da Escola de Enfermagem da USP, v. 35, n.2, p. 115-21, 2001.

IULINO, B.A.; MANCUSO, A.M. C.; GAMBARDELLA, A.M.D. Educação nutricional em escolas de ensino fundamental do município de Guarulhos-SP. O Mundo da Saúde, v. 33, n. 3, p. 264 - 272, 2009.

JUZWIAK, C.R.; CASTRO, P.M.; BATISTA, S.H.S.S. A experiência da Oficina Permanente de Educação Alimentar e em Saúde (OPEAS): formação de profissionais para a promoção da alimentação saudável nas escolas. Ciência \& Saúde Coletiva, v.18, n.4, p. 1009-1018, 2013. 
LEVY R.B et al. Distribuição regional e socioeconômica da disponibilidade domiciliar de alimentos no Brasil em 2008-2009. Revista de Saúde Pública, v.1, n. 46, p. 06-15, 2012.

PÉREZ GALLADO, L. et al. Utilidad de los programas de educación nutricional para prevenir la obesidad infantil a través de un estudio piloto en Soria. Nutrición Hospitalaria, v. 26, n.5, p. 1161-7, 2011.

PÉREZ LÓPEZ, I.J.; DELGADO FERNÁNDEZ, M. Un juego de cartas durante los recreos escolares mejora los hábitos alimentarios en adolescentes. Nutrición Hospitalaria, v. 27, n.6, p. 2055-2065, 2012.

PICCOLI, L.; JOHANN, R.; CORRÊA, E.N. A educação nutricional nas séries iniciais de escolas públicas estaduais de dois municípios do oeste de Santa Catarina. Nutrire: Revista da Sociedade Brasileira de Alimentação e Nutrição, v. 35, n. 3, p. 1-15, 2010.

PRADO, B.G. et al. Efeito de ações educativas no consume de alimentos no ambiente escolar. Nutrire: Revista da Sociedade Brasileira de Alimentação e Nutrição, v. 37, n. 3, p. 281-292, dez. 2012.

SANTOS, L.A.S. Educação alimentar e nutricional no contexto da promoção de práticas alimentares saudáveis. Revista de Nutrição, v.18, n.5, p. 681-692, 2005.

SANTOS, L.A.S. O fazer educação alimentar e nutricional: algumas contribuições para reflexão. Ciência \& Saúde Coletiva, v.17, n.2, p. 455-462, 2012.

SANTOS, L.A.S. et al. Formação de coordenadores pedagógicos em alimentação escolar: um relato de experiência. Ciência \& Saúde Coletiva, v.18, n.4, p. 993-1000, 2013.

SAVIANI, D. Escola e democracia. Campinas, São Paulo: Ed. Autores Associados Ltda., 2009. 90p.

SCHMITZ, B.A.S. et al. A escola promovendo hábitos alimentares saudáveis: uma proposta metodológica de capacitação para educadores e donos de cantina escolar. Cadernos de Saúde Pública, v.24, n.2, p. 312-322, 2008.

SOUZA, R.A.G. et al. Redução do uso de açúcar em escolas públicas: ensaio randomizado por conglomerados. Revista de Saúde Pública, v.47, n.4, p. 666-674, 2013.

TEO, C.R.P.A.; MONTEIRO, C.A. Marco legal do Programa Nacional de Alimentação Escolar: uma releitura para alinhar propósitos e prática na aquisição de alimentos.

Revista de Nutrição, v.25, n.5, p. 657-668, 2012.

VARGAS, I.C.S. et al. Avaliação de programa de prevenção de obesidade em adolescentes de escolas públicas. Revista de Saúde Pública, v.45, n.1, p. 59-68, 2011.

\section{Como referenciar este artigo}


BORSOI, Aline Tecchio.; TEO, Carla Rosane Paz Arruda.; MUSSIO, Bruna Roniza. Educação alimentar e nutricional no ambiente escolar: uma revisão integrativa. Revista Ibero-Americana de Estudos em Educação, Araraquara/SP, v. 11, n. 3, p.1441-1460, 2016. Disponível em: 〈https://dx.doi.org/10.21723/riaee.v11.n3.7413>. E-ISSN: 19825587.

Submetido em: 08/12/2014

Aprovação final em: 12/07/2016 